EDITOR:

- C.J. Eales, PhD

University of the Witwatersrand

AsSISTANT EDITOR:

- A. Stewart, MSc

University of the Witwatersrand

\section{EDITORIAL BOARD:}

NATiOnal Members

- S.L. Amosun, PhD

University of the Western Cape

- P. Gounden, PhD

University of Durban-Westville

- M. Papadoupolos, MSc

University of Pretoria

- M. Faure, MPhil

University of Stellenbosch

- N. Mbambo, MSc

MEDUNSA

\section{International Members}

- A. Akinpelu, PhD

University College Hospital, Ibadan, Nigeria

T.H.A. Kolobe, $\mathrm{PhD}$

University of Illinois, Chicago

- K. Shepard, PhD

Temple University, Philadelphia

- C. Partridge, $\mathrm{PhD}$

University of Kent, Canterbury

\author{
Review Panel: \\ - Amosun, Dele \\ - Bester, Ria \\ - Bowerbank, Pat \\ - Crous, Lynette \\ - David, Helen \\ - De Charmoy, Sue \\ - Diener, Ina \\ - Eksteen, Carina \\ - Eisenberg, Mashe \\ - Faure, Mary \\ Fearnhead, Lynn \\ - Frieg, Annette \\ - Fortune, Jessica \\ - Giraud, Jill \\ - Hunter, Linda \\ - Irwin-Carruthers, Sheena \\ - Kemp, Stephanie \\ - Mbambo, Noncebba \\ - M'kumbuzi, Vyvienne \\ - Mothabeng, Joyce \\ - Mpofu, Ratie \\ - Papadopoulos, Magda \\ - Paulsen, Tom \\ - Potterton, Joanne \\ - Puckree, Lina \\ - Smith, Elsa \\ - Swartz, Alma \\ - Uys, Marietta \\ - Van Rooijen, Tanya
}

\title{
Challenges Facing PHYSIOTHERAPY EDUCATION
}

$\mathrm{P}$ hysiotherapy education is facing interesting challenges due to the socio-political changes that have taken place in South Africa since 1992. Change in education is dependent as superficial in which teaching takes place. Such a way of change is usually change for the sake of change. However, change can also be a fundamentally different way of implementing strategies, based on a paradigm shift due to a different perspective of the world around you. This latter type of change is difficult to pursue because it constantly requires re-evaluation of the new direction, adjusting and implementing the action plans, ensuring that the new direction adheres to scientifically and fundamentally sound principles of the changes / new paradigm.

The changes in physiotherapy education described in the literature encompass a change in the compilation of the traditional curriculum into a problem based curriculum, as well as change in the teaching approach, namely from an emphasis on lecturing to the problem based learning approach. Problem-based Learning (PBL) has become almost a "buzzword" in physical therapy education in recent years. Thus, a literature review and discussion are important and salient at this time when many developing educational programs are embracing this method of instruction (Hayes, 1998). Albanese and Mitchell (1993) suggest that a PBL program may not develop the desired knowledge structure, which is a scientific and theoretical foundation upon which to build a base of understanding in order to make sound diagnoses and to practice independently (Ibid). The reason for this is twofold: firstly the foundational principles that need to be in place for implementing PBL have not been described fully and secondly there is a lack of evidence that one educational method or approach is better than another. Foundational principles that need to be in place would be an understanding of the substantive and syntactical structure of the discipline that is being learned. Amongst other things, the core of the matter is that it entails an understanding of the thinking structure (the relationship between the facts, concepts, principles used in the discipline), as well as the skills needed in the process of generating new knowledge in the discipline. This leads to the situation that every institution implements and adapts PBL according to its own circumstances and facilities. This causes a situation that PBL programs can not be compared to one another due to foundational differences in the compilation of the programs. The reason for the lack of scientific evidence that one educational method or approach is better than another this is that the research design of educational programs or techniques are often poorly developed and/or described. This makes comparison between the effects of educational approaches or techniques impossible. Comparison between educational approaches or techniques to determine what constitutes 'best practice' is called best evidence medical education (BEME), which is similar to evidence based physiotherapy practice. BEME is also based on a systematic review of research and is based on systematic review of research in education, social science, criminology, etcetera. The process of systematic review in health care education is developed by the Campbell Collaboration, a similar organization to the Cochrane Collaboration (Belfield, et al 2001).

All research in health care (and also physiotherapy) education needs to take 
place on a sound fundamental and scientific foundation, which serves as point of reference for developing a research protocol as well as interpreting the results. In this regard Campbell and Johnson (1999) states: One barrier to true debate is a lack of conceptual clarity. Authors do not need to be unanimous in their definition of a concept, but they must be clear about their conceptualisation.

Belfield et al (2001) describe five levels of effectiveness according to which the effectiveness of educational strategies and interventions can be measured, namely:

i) highest level impact on the delivery of health care which includes that graduates make fewer errors in practice due to a difference in educational strategy;

ii) proof of a change in health professionals' behaviour, performance or practice;

iii effective learning or knowledge acquisition due to an educational strategy; iv) learners' reaction to or satisfaction with the educational strategy;

v) the lowest level, participation or completion of a learning task. Participation or completion may at its lowest level even include a financial audit and state that participation of learners was satisfactory or not.

Such a scale and hierarchical classification of terms makes it possible to compare evidence of effects across a range of teaching methods and approaches. Belfield et al (2001) advise that researchers plan and implement the methodology of educational research projects with the aim being to measure the effectiveness of a specific strategy in more than one of the outcome measures of effectiveness in order to form a balanced opinion on the effectiveness of the educational strategy. The fact that the outcome of educational strategies or approaches as well as instructional techniques can be measured reduces the incidence of implementing educational strategies just because it is in 'fashion'
Implementing such 'fashion' strategies without critically evaluating them, is detrimental to the development of health care education and in the long run also for facilitating the development of health of care professionals.

\section{REFERENCES}

Albanese M A, Mitchell S 1993 Problem based learning: a review of literature on its outcomes and implementation issues. Academic Medicine 68

Belfield C, Thomas H, Bullock A, Eynon R, Wall D 2001 Measuring effectiveness for best evidence medical education. Medical Teacher 23(2)

Campbell J K, Johnson C 1999 Trend spotting: fashions in medical education, British Medical Journal 318

Hayes S H 1998 Problem-Based Learning in Physical Therapy: A Review of the literature and Overview of the McMaster University Experience. Invited Commentary. Physical Therapy 78(2)

\title{
THE SOUTH AFRICAN IOURNAL OF PHYSIOTHERAPY
}

\section{All correspondence to the editor must be addressed to:}

\author{
Prof CJ Eales - Editor SASP Journal,
}

Department of Physiotherapy, Faculty of Health Sciences,

7 York Road, Parktown 2193

E-mail:159eales@chiron.wits.ac.za

159garsl@chiron.wits.ac.za 